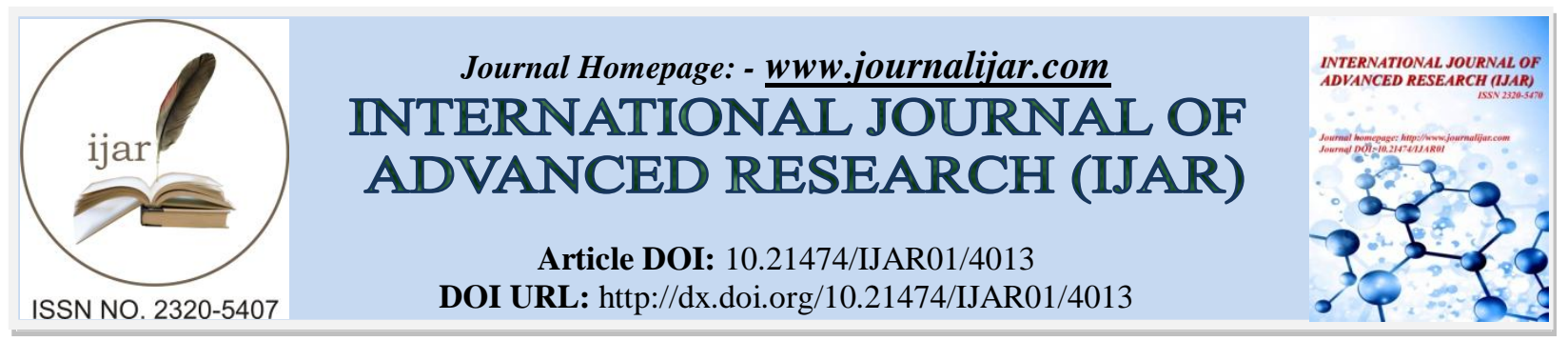

RESEARCH ARTICLE

\title{
EFFECT OF VISUAL PROMPTING TECHNIQUE ON BASIC SAFETY STRATEGIES AGAINST SEXUAL ABUSE AMONG GIRLS WITH LOW VISION
}

\author{
Dr. R. Jamuna. \\ Assistant Professor, Indira Gandhi College of Special Education, kanuvai Coimbatore, Tamilnadu, India.
}

\section{Manuscript Info}

Manuscript History

Received: 20 February 2017

Final Accepted: 17 March 2017

Published: April 2017

Key words:-

Video prompting, Picture prompting,

Low vision, Girls, Basic safety

strategies, Sexual abuse

\begin{abstract}
This study was designed to evaluate the effect of visual prompting technique on basic safety strategies against sexual abuse among girls with low vision. Thirty girls with low vision belonging to the age group of 6-10 years were selected from four schools, teaching children with special needs. Quasi experimental study was conducted with pre, post and single group design.. The result showed that visual prompting technique was highly effective in imparting the concept of basic safety strategies against sexual abuse among girls with low vision children.
\end{abstract}

Copy Right, IJAR, 2017,. All rights reserved.

\section{Introduction:-}

Abuse of child with disability includes any threatening or violent interaction of physical, psychological or sexual nature that may be the reason for physical or psychological harm to the child. This includes neglect and withholding essential aid, medical care and education. Children with disabilities have the right to protect from all forms of maltreatment, abuse, neglect and violence. Unfortunately, children with disabilities are at even greater risk for child abuse. Children with disability are in need of self protection skills because of the largely negative attitudes of caregivers and parents about the sexuality of these individuals. Their sexuality is either ignored or perceived as a problem so it is the need of the hour to provide adequate sex education to protect the rights of this population.

\section{Objectives:-}

$>$ To study the knowledge of basic safety strategies against sexual abuse among girls with low vision

$>$ To evaluate the effect of visual prompting technique in imparting knowledge on basic safety strategies against sexual abuse among girls with low vision.

\section{Need for the study:-}

In today's scenario abuse is common to all females; there is no disparity or partiality in age, colour, caste, society and particularly the disability. Disabled children are more vulnerable to different kinds of abuses. First, these children often depend on others for activities of daily living. This dependency creates the necessity for intensive interactions with caregivers. When the caregivers have the potential to be abusive, their interactions with caregivers are readily exploited. Second, children with disabilities often do not have proper personal safety vocabulary necessary to report instances of child abuse (Alyott, 1995; Petersilia, 2000).

The goal of teaching basic concepts on safety strategies against sexual abuse to the children with disabilities is to identify a potentially dangerous situation, to respond safely to the situation by verbally refusing and/or leaving the situation, and to report the situation. 


\section{Description of the intervention:-}

Video prompting is a form of video instruction that breaks down target skills into steps that are then performed directly after viewing each clip. The intervention was given on the area of basic safety strategies which includes, identifying the body parts, differentiating the private and public parts, reporting skills, communication skills, warning signs, types of touches and No, Go, and Tell strategy. The concepts were prepared in video clippings with audio explanation and picture booklets with explanation in regional language.

\section{Review of literature:-}

Spector, Merrill, Van Merrienboer, and Driscal, 2008 says that that the visual channel handles less information than the auditory channel. However, when information is presented using both the visual and auditory channels, working memory can handle more information overall.

Mayer and Sweller, 2005 carried out research in the area of using picture and words in multimedia learning that, People learn better from words and pictures than from words alone. In this context, words include written and spoken text, and pictures include static graphic images, animation and video. That using both words and pictures is more effective than words alone or pictures alone should not be surprising in light of what we know about how the brain processes information. Research tells us that the use of both words and pictures lets the brain process more information in working memory

\section{Methodology:-}

Purposive sampling technique was used to select thirty girls with low vision from inclusive schools and special schools. Quasi experimental design was used with single group, pre test was conducted by situ test. The intervention was given for a period of three months each on the basis of concrete to semi abstract method i.e video clippings were introduced first, and then the picture booklet was given. Closed circuit television was used to display the video clippings with audio explanation. Low vision aid magnifier was provided to the children to see the pictures and written explanation in regional language to use the picture booklet. The content explained in both the techniques were similar, so the subjects had enough input to understand the concepts easily. Each technique was intervened for three months, and after three months post test was conducted using the situ test.

\section{Results and Discussion:-}

Analysis of mean scores on basic safety strategies against sexual abuse among girls with low vision

\begin{tabular}{|c|c|c|c|c|c|c|}
\hline Skill & No & Df & Testing & Mean & S.D & t Value \\
\hline \multirow{2}{*}{$\begin{array}{l}\text { Identification of } \\
\text { body parts }\end{array}$} & \multirow[t]{2}{*}{30} & \multirow[t]{2}{*}{29} & Before & 7.00 & 2.90 & \multirow[t]{2}{*}{$3.48 * *$} \\
\hline & & & After & 8.97 & 1.52 & \\
\hline \multirow{2}{*}{$\begin{array}{l}\text { Knowledge on } \\
\text { private and } \\
\text { public parts }\end{array}$} & \multirow[t]{2}{*}{30} & \multirow[t]{2}{*}{29} & Before & 1.67 & 2.48 & \multirow[t]{2}{*}{$9.80 * *$} \\
\hline & & & After & 7.33 & 1.79 & \\
\hline \multirow{2}{*}{$\begin{array}{l}\text { Types of } \\
\text { touches }\end{array}$} & \multirow[t]{2}{*}{30} & \multirow[t]{2}{*}{29} & Before & 3.03 & 2.97 & \multirow[t]{2}{*}{$7.82 * *$} \\
\hline & & & After & 7.40 & 2.28 & \\
\hline \multirow[t]{2}{*}{ Reporting } & \multirow[t]{2}{*}{30} & \multirow[t]{2}{*}{29} & Before & 4.13 & 3.12 & \multirow[t]{2}{*}{$5.27 * *$} \\
\hline & & & After & 7.30 & 2.29 & \\
\hline \multirow{2}{*}{$\begin{array}{l}\text { No, Go, Tell } \\
\text { Strategy }\end{array}$} & 30 & 29 & Before & 7.33 & 1.79 & $2.9 * *$ \\
\hline & & & After & 9.07 & 0.37 & \\
\hline \multirow[t]{2}{*}{ Warning signs } & 30 & 29 & Before & 0.13 & 0.35 & $6.04 * *$ \\
\hline & & & After & 3.27 & 2.79 & \\
\hline
\end{tabular}

The above table portrays that the ' $t$ ' value is 3.48 for Girls with low vision in identification of body parts which is significant at $1 \%$ level. The table indicates that mean scores of identification of body parts before and after intervention differed significantly. Therefore the null hypothesis stated as "there is no significant difference in 
mean scores of identification of body parts before and after introduction of Visual Prompting Techniques” is rejected. It means that there was a significant impact of Visual Prompting Techniques on identification of body parts among the girls with low vision.

It is clear that the ' $t$ ' value is 9.8 for Girls with low vision in Knowledge on private and public parts which is significant at $1 \%$ level, reflecting that mean scores of Knowledge on private and public parts before and after intervention differed significantly. Therefore the null hypothesis stated as "there is no significant difference in mean scores of Knowledge on private and public parts before and after introduction of Visual Prompting Techniques" is rejected. It means that there was a significant impact of Visual Prompting Techniques on Knowledge on private and public parts among the girls with low vision.

The table value reveals that the correlated ' $t$ ' value is 7.82 for Girls with low vision in the knowledge on Type of touches which is significant at $1 \%$ level. It reflects that pre and post mean scores of Type of touches before and after intervention differed significantly. Therefore the null hypothesis stated as "there is no significant difference in mean scores of Type of touches before and after introduction of Visual Prompting Techniques” is rejected. It means that there was a significant impact of Visual Prompting Techniques on Type of touches This study was designed to evaluate the effect of visual prompting technique on basic safety strategies against sexual abuse among girls with low vision. Thirty girls with low vision belonging to the age group of 6-10 years were selected from four schools, teaching children with special needs. Quasi experimental study was conducted with pre, post and single group design.. The result showed that visual prompting technique was highly effective in imparting the concept of basic safety strategies against sexual abuse among girls with low vision children.

It depicts the significant ' $t$ ' value is 5.27 for Girls with low vision in Reporting to which is significant at $1 \%$ level. It indicated that the post mean scores of girls with low vision with respect to Reporting differed significantly. In the light of this the null hypothesis stated as "there is no significant difference in mean scores of Reporting before and after introduction of Visual Prompting Techniques" is rejected. It means that there was a significant impact of Visual Prompting Techniques for reporting among the samples.

It was also evident that the ' $t$ ' value is 2.99 for Girls with low vision in No, Go, Tell Strategy which is significant at $1 \%$ level. It indicated that the post mean scores of girls with low vision with respect to No, Go, Tell Strategy differed significantly. In the light of this the null hypothesis stated as "there is no significant difference in mean scores of No, Go, Tell Strategy before and after introduction of Visual Prompting Techniques” is rejected. It means that there was a significant impact of Visual Prompting Techniques for No, Go, Tell Strategy among the samples.

It was also evident that the ' $t$ ' value is 6.04 for Girls with low vision in Warning signs which is significant at $1 \%$ level. It indicated that the post mean scores of girls with low vision with respect to Warning signs differed significantly. In the light of this the null hypothesis stated as "there is no significant difference in mean scores of Warning signs before and after introduction of Visual Prompting Techniques” is rejected. It means that there was a significant impact of Visual Prompting Techniques for Warning signs among the samples.

\section{Conclusion:-}

From the results it is very clear that the video clippings audio explanation and picture booklet with written explanation enhanced the learning of basic safety strategy against sexual abuse among girls with low vision. This basic knowledge will help the girls with low vision to protect them from abusive situation. 


\section{Reference:-}

1. Spriggs, A. D., Gast, D. L., \& Ayres, K. M. (2007). Using picture activity schedule books to increase onschedule and on-task behaviors. Education and Training in Developmental Disabilities, 42, $209-223$

2. Wacker, D. P., Berg, W. K., Berrie, P., \& Swatta, P. (1985). Generalization and maintenance of complex skills by severely handicapped adolescents following picture prompt training. Journal of Applied Behavior Analysis, $18,329-336$

3. Wacker, D. P., Berg, W. K., Berrie, P., \& Swatta, P. (1985). Generalization and maintenance of complex skills by severely handicapped adolescents following picture prompt training. Journal of Applied Behavior Analysis, $18,329-336$

4. R.E. Mayer (Ed), The Cambridge Handbook of Multimedia Learning. New York: Cambridge University Press, 2005.

5. J.M. Spector, M.D. Merrill, J. van Merriënboer, \& M.P. Driscoll (Eds), Handbook of Research on Educational Communications and Technology. Third Edition. New York: Taylor Francis Group, 2008 